\title{
Rhodiola rosea in Subjects with Prolonged or Chronic Fatigue Symptoms: Results of an Open-Label Clinical Trial
}

\author{
Yevgeniya Lekomtseva ${ }^{a}$ Irina Zhukovab Anna Wacker ${ }^{\mathrm{c}}$ \\ ${ }^{a}$ State Institute of Neurology, Psychiatry and Narcology, National Academy of Medical Sciences of Ukraine, Neuroimmunology and \\ Headache Department, Kharkiv, Ukraine \\ ${ }^{b}$ Neurology Department, Tomsk Medical University, Tomsk, Russia; \\ ${ }^{c}$ Dr. Willmar Schwabe GmbH \& Co. KG, Karlsruhe, Germany
}

\section{Keywords}

Chronic fatigue - Clinical trial - Prolonged fatigue . Rhodiola rosea $\cdot$ Rosalin $\cdot$ WS ${ }^{\circledR} 1375$

\section{Summary}

Background: Rhodiola rosea roots and rhizomes are a herbal medicine for temporary relief of stress symptoms such as fatigue and sensed weakness. A daily dosage of $400 \mathrm{mg}$ is recommended. Methods: A dry ethanolic extract of $R$. rosea (WS ${ }^{\circledR}$ 1375) was studied in 100 subjects with prolonged or chronic fatigue symptoms. In an uncontrolled, open-label multicenter clinical trial, the subjects were administered $2 \times 200 \mathrm{mg} \mathrm{WS}^{\circledR} 1375$ over 8 weeks. Outcome measures were scales and tests related to fatigue. They were evaluated in an exploratory data analysis to generate hypotheses regarding efficacy. The pilot character of the trial is marked by its broad focus on subjects suffering from fatigue in general and by its comparatively long duration. Results: The greatest change was observed after 1 week of treatment. The fatigue symptoms continued to decline further, with statistically significant improvement at week 8 . The safety assessments of WS ${ }^{\circledR} 1375$ during the trial proved to be favorable, with most adverse events being of mild intensity and not related to the study drug. Conclusions: The results indicate that $2 \times 200 \mathrm{mg} \mathrm{WS}^{\circledR} 1375$ may be an effective treatment in subjects suffering from prolonged or chronic fatigue. The safety and tolerability of WS ${ }^{\circledR} 1375$ also presented a favorable profile.

(c) 2017 The Author(s). Published by S. Karger GmbH, Freiburg

\begin{tabular}{ll}
\hline KARGER & $\begin{array}{l}\text { (c) } 2017 \text { The Author(s) } \\
\text { Published by S. Karger GmbH, Freiburg Oparger }\end{array}$ \\
$\begin{array}{l}\text { Fax }+497614520714 \\
\text { Information@Karger.com }\end{array}$ & $\begin{array}{l}\text { This article is licensed under the Creative Commons Attribution- } \\
\text { NonCommercial-NoDerivatives 4.0 International License (CC BY-NC- } \\
\text { ND 4.0) (http://www.karger.com/Services/OpenAccesLicense). Usage } \\
\text { www.karger.com }\end{array}$ \\
& and distribution for commercial purposes as well as any distribution of
\end{tabular}

\section{Schlüsselwörter}

Chronische Erschöpfung · Klinische Studie . Andauernde Erschöpfung · Rhodiola rosea - Rosalin . WS ${ }^{\circledR} 1375$

\section{Zusammenfassung}

Hintergrund: Die Wurzeln und Rhizome von Rhodiola rosea werden als Heilpflanze zur vorübergehenden Linderung von Stresssymptomen wie Erschöpfung oder Schwächegefühl eingesetzt. Die empfohlene Tagesdosis liegt bei 400 mg. Methoden: Das Studienmedikament, ein ethanolischer Trockenextrakt aus $R$. rosea (WS ${ }^{\circledR}$ 1375), wurde bei 100 Patienten mit Symptomen andauernder oder chronischer Erschöpfung angewendet. Den Teilnehmern wurde im Rahmen einer unkontrollierten, offenen, multizentrischen klinischen Studie über die Dauer von 8 Wochen eine Tagesdosis von $2 \times 200$ mg WS $^{\circledR} 1375$ verabreicht. Messgrößen waren erschöpfungsbezogene Skalen und Tests, die auf exploratorischer Ebene hinsichtlich der Wirksamkeit von WS ${ }^{\circledR} 1375$ ausgewertet wurden. Der breite, auf Fatigue-Patienten im Allgemeinen ausgerichtete Fokus sowie die vergleichsweise lang angesetzte Dauer kennzeichnen den Pilotcharakter der Studie. Ergebnisse: Die größten Veränderungen der Analysewerte wurden nach 1 Woche Behandlungsdauer gemessen. Die Erschöpfungssymptome gingen danach weiter zurück und hatten sich bis Woche 8 statistisch signifikant verbessert. Die Sicherheitsbewertung von WS ${ }^{\circledR} 1375$ während der Studie fiel günstig aus, da die meisten unerwünschten Ereignisse von milder Ausprägung und nicht dem Studienmedikament zuzuordnen waren. Schlussfolgerungen: Die Resultate lassen auf einen Behandlungseffekt von $2 \times 200$ mg WS ${ }^{\circledR} 1375$ bei Patienten mit andauernder oder chronischer Erschöpfung schließen. Günstige Ergebnisse zeigten sich auch in Bezug auf die Sicherheit und Verträglichkeit von WS ${ }^{\circledR} 1375$. 


\section{Introduction}

Fatigue is commonly defined as a feeling of tiredness, lack of energy, emotional stability and motivation, or difficulty in concentration and memory $[1,2]$. The clinical course is frequently aggravated by a variety of attending symptoms such as headache or muscle pain. Applicable duration categories are: recent fatigue: $<1$ month; prolonged fatigue: 1-6 months; chronic fatigue: $>6$ months $[2,3]$.

While earlier data suggest the prevalence of the chronic fatigue syndrome (CFS) to be at about $0.04 \%$ or even less [4], a recent study from The Netherlands shows that approximately $1 \%$ of the adult population reported complaints that correspond to chronic fatigue symptoms according to the Center of Disease Control (CDC) criteria [5]. This study and other recent studies [5-8] state that up to one-third of the adult population has experienced fatigue symptoms not fully meeting the CDC criteria. These recent findings suggest that chronic fatigue and related symptoms might be more common than previously thought.

The considerable number of chronic fatigue-related symptoms expected to exist among the adult population, as well as the unfavorable condition that no standard medication is as yet available [4, 9], encouraged us to conduct a trial on the effects of Rhodiola rosea in patients who had experienced fatigue over a period of at least 2 months and who thus would form a cohort representing fatigue without further specifications. As chronic fatigue is likely to result from a prolonged lack of fatigue treatment [10], the identification of an efficient and safe fatigue therapy, also in rather mild or prolonged, not yet chronic cases, was regarded to be even more warranted.

Given the probability of multiple etiologies for prolonged or chronic fatigue, a promising approach towards a successful therapy is offered by the concept of adaptogens, which refers to substances traditionally applied to improve mental and physical performance. Adaptogens are considered to be nearly non-toxic and of non-specific effect, thus being capable of generally strengthening the organism against adverse factors like stress [11]. Stress is considered a major possible precondition for the onset of fatigue [12-14].

$R$. rosea is reported to have adaptogenic properties [15-17]. The root stock contains 6 distinct groups of active compounds, among which the phenylpropanoids rosavin and rosarin are considered to occur only in $R$. rosea $[18,19]$. Due to its adaptogenic features, $R$. rosea belongs to those herbal medicines that are reported to improve mental performance and enhance endurance in fatigue [20]. The recommended daily dosage of $R$. rosea is $400 \mathrm{mg}$ [21].

Recent studies have demonstrated that $R$. rosea can reduce mental fatigue under stressful conditions [22-24] or conditions of ongoing life-stress symptoms [25]. A controlled trial showed the superiority of $R$. rosea over placebo in improving mental fatigue as measured by the Pines burnout scale [26]. Furthermore, results from animal studies suggest a stimulating effect of $R$. rosea on the physical work capacity [27].

As to date no standard medication is available to effectively treat presentations of fatigue $[4,9]$, the objective of the presented trial was to gain insights into the therapeutic effects of $R$. rosea in patients who had experienced fatigue over a period of at least 2 months. Other than most of the preceding studies which examined a specified range of fatigue patients such as night-shift workers or examinees, in this trial a narrow subject definition was abandoned in order to find results applicable to a wide range of fatigue patients. Also, the duration of the trial was comparatively longer than in most studies on $R$. rosea in fatigue patients performed to date [28].

\section{Methods}

\section{Trial Design and Setting}

The present study was conducted to evaluate the therapeutic effect, safety, and tolerability of the dry ethanolic $R$. rosea extract WS ${ }^{\circledR} 1375$ (Rosalin; Rosalin is the active substance of Vitango ${ }^{\circledR}$, manufactured by Dr. Willmar Schwabe GmbH \& Co. KG, Germany) (drug/extract ratio 1.5-5:1). The objective of this trial was to describe the named outcomes of WS ${ }^{\circledR} 1375$ in subjects with symptoms of prolonged and chronic fatigue. The study aimed at obtaining results applicable to as many subjects as possible suffering from fatigue.

This trial was designed as an open-label, single-arm, multicenter study. It was conducted at the Neurology Departments of 5 hospitals in Ukraine. Planning, execution, and analysis of the trial were carried out in accordance with the national regulations. The study followed the International Conference on Harmonization of Technical Requirements for Registration of Pharmaceuticals for Human Use (ICH) Guidelines for Good Clinical Practice and the Declaration of Helsinki for Humans. In order to ensure the reliability of data obtained at the respective sites, investigators received extensive rater training by expert trainers selected by the sponsor prior to study initiation.

Trial duration was 8 weeks; the study medication was administered as 2 tablets daily, each containing $200 \mathrm{mg}$ of WS ${ }^{\circledR} 1375$.

\section{Outcome Measures}

Treatment effects were measured by changes of stress symptoms, fatigue, quality of life, mood, concentration, and general health. Safety and tolerability were monitored by comparison of physical examinations, laboratory data, and vital signs measurements between baseline and end of treatment, and by adverse event (AE) screening. The following scales were employed:

- Multidimensional Fatigue Inventory 20 (MFI-20): The MFI-20 is a validated 20-item self-report instrument designed to measure fatigue [29, 30]. It consists of 5 subscales of fatigue: general fatigue, physical fatigue, mental fatigue, reduced motivation, and reduced activity.

- Numeric Analogue Scales (NASs) of chronic fatigue symptoms according to CDC definition: 3 self-rating NASs assessing 'postexertional malaise', 'impairment of concentration/memory', and 'nonrestorative sleep' were applied.

- Numbers Connecting Test (NCT): The NCT [31] is a language-free, timed test to assess the speed of executive function.

- Sheehan Disability Scale (SDS): The SDS is a validated 3-item self-report inventory designed to assess the degree to which symptoms of panic, anxiety, depression, or phobia have disrupted the patient's work, social life, and family life [32].

- Pittsburgh Sleep Quality Index (PSQI): The PSQI [33] is a validated selfrated questionnaire that assesses sleep quality and disturbances retrospectively over a 4-week time interval.

- Recent Perceived Stress Questionnaire (PSQ-R): The 30-item PSQ-R is a self-rating instrument to assess subjectively experienced stress [34].

- Beck Depression Inventory II (BDI-II): The BDI-II is a validated 21-item questionnaire designed to assess symptoms of depression such as sadness, guilt, loss of interest, social withdrawal, and suicidal ideation [35].

- Clinical Global Impressions (CGI): The CGI scales are widely used as validated measures of treatment outcome [36]. Ratings are recorded during an interview between investigator and patient and then evaluated by the former. In this trial, only the items 'change from baseline', 'therapeutic effi- 
cacy', and 'tolerability' were employed and evaluated on the Clinical Global Impression of Change scale.

All outcome measures, except the CGI, were assessed right after the patient had been enrolled in the study and before the first dose of study medication was administered. The patients were asked to return for follow-up visits after 1, 4, and 8 weeks.

The outcome measures of the MFI-20, NASs, NCT, SDS, and CGI were collected at weeks 1,4 , and 8 . The PSQI, PSQ-R, and BDI-II results were collected at weeks 4 and 8 .

Self-rating scales were completed by the participants at the predefined times. All other scales were assessed by the investigator at the respective study site.

\section{Safety Measures}

In addition to the efficacy results, safety outcome variables were assessed at baseline and at week 8 or at an early termination visit, including physical examination, vital signs, 12-lead electrocardiography (ECG), and laboratory tests. All AEs were recorded in AE report forms by the respective investigator.

\section{Participants}

It was planned to recruit 100 male and female outpatients aged 18-60 years with prolonged or chronic fatigue symptoms.

The following inclusion criteria had to be met:

- Clinically evaluated, unexplained persistent or relapsing fatigue symptoms lasting for at least 2 months that were not the result of ongoing exertion, not substantially relieved by rest, and leading to substantial reduction in previous levels of occupational, educational, social, or personal activities.

- Chronic fatigue symptoms assessed as $\geq 5$ on the NASs for 'postexertional malaise lasting more than 24 hours', 'substantial impairment in short-time memory and concentration', and 'unrefreshing sleep'.

- MFI-20 score $\geq 7$ for the subscales 'general fatigue', 'physical fatigue', 'mental fatigue'.

- Sufficient language skills, readiness and ability to comply with the physician's instructions, to respond to all interview questions and to fill in the self-assessment scales without evident difficulties and without the assistance of an interpreter.

\section{Exclusion criteria were:}

- Participation in another drug trial; current hospitalization; BDI-II item $9 \geq$ 1 ; history/evidence of substance abuse or dependence within the last 5 years history of Axis I disorders according to the Diagnostic and Statistic Manual of Mental Disorders (DSM)-IV at least 1 year before enrolment; nonmedical psychiatric treatment at least 4 weeks before the study; unacceptability to discontinue or likelihood to need any psychotropic drugs, clinically significant abnormality of ECG or laboratory values, cardiovascular diseases, respiratory diseases, metabolic disorders or progressive diseases, cerebrovascular and neurologic diseases, any acute, latent, or chronic form of infection; gastrointestinal disorders with uncertain absorption of orally administered drugs; pregnancy or lactation and known hypersensitivity to $R$. rosea extract, insufficient contraception in pre-menopausal women.

\section{Baseline Examinations}

Medical history and concomitant diseases/medication were assessed at the screening visit (day -2). Also, a physical examination was performed by a physician at the screening visit and at study termination (week 8). Further examinations performed at baseline (day 0) were a 12-lead ECG, standard laboratory tests of blood samples (hematology, metabolites, liver enzymes, coagulation parameters, and electrolytes), and urine analysis using urine sticks for the presence of proteins, blood, and glucose. The screening visit included a first completion of all questionnaires involved, except for the CGI.

Signed informed consent according to ICH regulations was obtained at the screening visit. The overall examination of subjects at the screening visit, medical history anamnesis, and physical and neurological examination were performed by a physician in accordance with standard procedures at the investigation site. Hematology and clinical chemistry tests were done by 1 central laboratory.

\section{Intervention}

Treatment started on the morning of day 1 . Patients were asked to take one 200-mg tablet before breakfast and one before lunch, with a glass of water.

\section{Statistical Methods}

Since this study was an open-label exploratory trial, no hypotheses were formulated and the data were analyzed to be reported descriptively.

In order to investigate the therapeutic effects of WS ${ }^{\circledR} 1375$ in subjects with symptoms of prolonged or chronic fatigue during 8 weeks of treatment, the absolute and relative intra-individual changes of the outcome parameters between baseline and end of treatment were evaluated. Also, time courses of the outcome parameters were analyzed. Descriptive statistics were computed to describe the empirical distributions; 95\% confidence intervals (CIs) for the expected values and medians were calculated. Accordingly, the resulting p-values (2-sided p-values of the Wilcoxon signed-rank test) and the phrase 'statistical significance' have to be interpreted in an exploratory sense.

Analysis was primarily based on the full analysis set (FAS) including all subjects having received the study drug at least once and having had at least 1 measurement of one of the rating scales during the treatment period. Missing values of some items or total scores during the treatment period were replaced by the last observation carried forward (LOCF) method.

Due to the exploratory character, no adjustments for multiplicity were applied and no formal estimation of sample size accounting for type I error rate, power, standard deviation (SD), and effect size was done. The definition of the sample size of 100 subjects was done based on the fact that analyzing 100 datasets results in an $80 \%$ power to detect a minimum standardized difference of 0.5 within a 1-group multivariate repeated measures design for a 2 -sided test, 4 time points, and a descriptive significance level $\alpha=0.05$ [37].

The case report form (CRF) data were double-entered into the database by independent, trained personnel. The system used for this purpose was the validated Clinical Trial Management System 'Clincase Software 2.6'. Statistical analyses were performed using SAS ${ }^{\circledR}$ version 9.2 (SAS, Cary, NC, USA).

\section{Results}

\section{Demographic Characteristics at Baseline}

In total, 112 subjects were screened for inclusion. Each center recruited between 8 and 27 subjects. 11 of the screened subjects were not included into the treatment phase due to screening failure, without any intake of the investigational product. The remaining 101 subjects were enrolled and received the investigational treatment at least once. During the treatment phase, 1 subject terminated the study prematurely due to violation of the exclusion criteria. The FAS therefore comprised 100 subjects, 31 male, $69 \mathrm{fe}-$ male ones. The mean age was $37.8 \pm 9.5$ years; the mean weight was $72.1 \pm 13.5 \mathrm{~kg}$. The first subject was included in December 2011; the last visit of the last patient was conducted in May 2012.

\section{Outcome Measures}

All outcome measures are presented with regard to the FAS.

The evaluation of the MFI-20 assessments reveals a significant improvement in all subscales $(\mathrm{p}<0.0001)$. The greatest change was found for the subscale 'general fatigue' with a difference to baseline of $8.2 \pm 4.1$ points at week 8 . For the subscales 'physical fatigue', 'mental fatigue', 'reduced activity', and 'reduced motivation', change values of $6.9 \pm 4.4,6.0 \pm 3.9,6.5 \pm 4.3$, and $3.3 \pm 3.3$, respectively, were found at the end of treatment. In all MFI-20 subscales, the most pronounced change occurred in the course of week 1. Improvement continued up to the end of the trial (fig. 1). 
On all NASs for chronic fatigue symptoms according to CDC, significant improvements between the screening visit and the following visits were found $(\mathrm{p}<0.0001)$. The degrees of improvement were similar among the different scales (fig. 2).

Significant improvement was also demonstrated for most values assessed by the SDS in week 8 compared to baseline. The outcome measures for 'impairment at work', 'impairment in social life', and 'impairment in family life' improved considerably (table 1).

Values measured by the NCT markedly improved in the course of the trial. The mean total score of the NCT decreased significantly from $103.4 \pm 40.8 \mathrm{~s}$ to $85.1 \pm 37.1 \mathrm{~s}$ with a difference of $18.4 \pm 17.2 \mathrm{~s}$ between screening and week $8(\mathrm{p}<0.0001)$.

The PSQ-R score decreased in the course of the treatment and

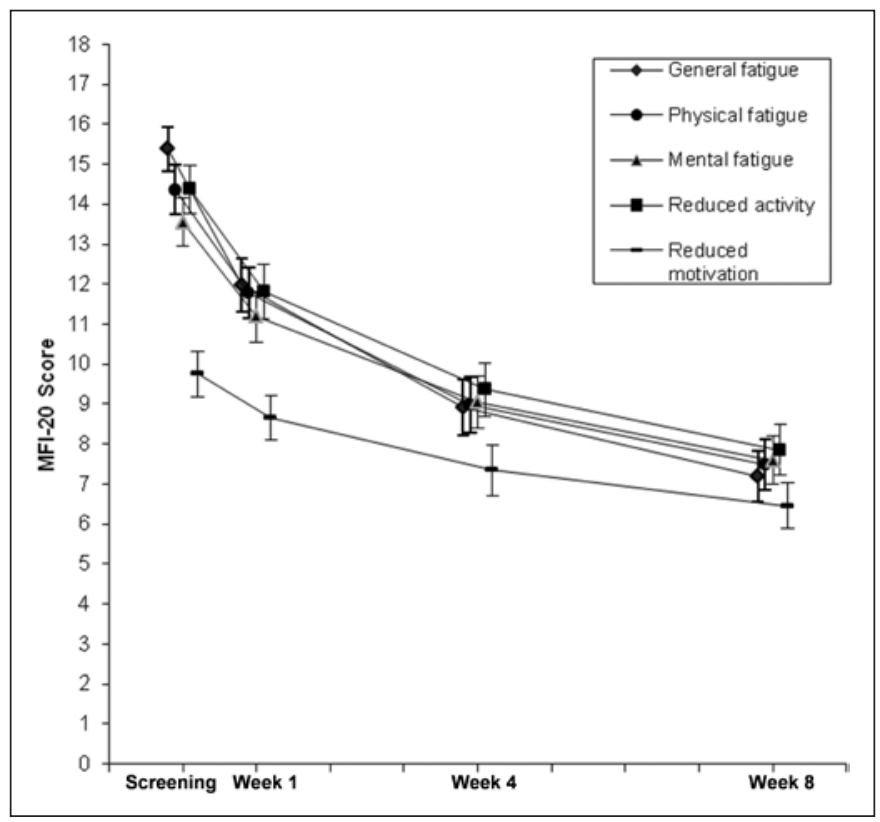

Fig. 1. Multidimensional Fatigue Inventory 20 (MFI-20): Time course of single items between screening and week 8 (mean and 95\% CI, FAS, $\mathrm{n}=100$, LOCF). was reduced by $0.2 \pm 0.2$ points at week $8(\mathrm{p}<0.0001)$, which corresponds to a mean reduction of the total stress score by $41.8 \%$. Among the PSQ-R subscores, the 'fatigue' value had decreased by $38.8 \%$ at week 8 and was thus the PSQ-R subscore with the greatest improvement $(\mathrm{p}<0.0001)$ (table 2$)$.

The mean PSQI total score decreased from $8.0 \pm 3.1$ to $4.8 \pm 2.5$ between screening and week 4 and continued to decrease further, resulting in an average PSQI total score of $3.7 \pm 2.2$ after 8 weeks of treatment. Both differences were statistically significant $(\mathrm{p}<0.0001$ both). Similar to the total score, all subscores of the PSQI decreased significantly from week 4 onwards.

The mean total score of the BDI-II improved from a screening score of $10.8 \pm 5.0$ to $5.6 \pm 4.5$ and $4.0 \pm 4.3$ at week 4 and week 8 , respectively ( $\mathrm{p}<0.0001$ each).

With regard to the CGI global improvement, 83/100 (83.0\%) subjects reported 'very much' or 'much' improved conditions at

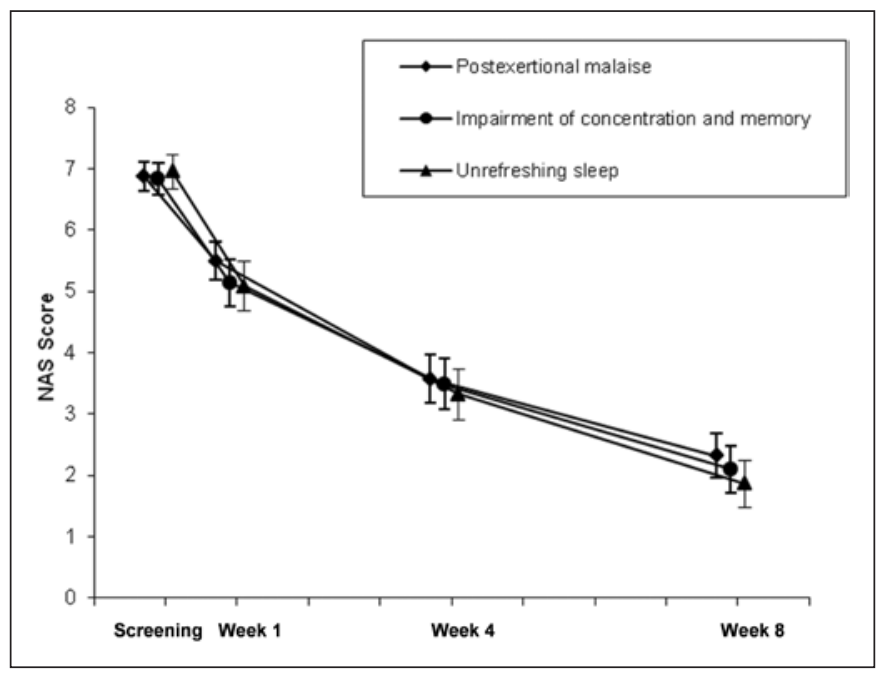

Fig. 2. Three Numerical Analogue Scales (NASs) of chronic fatigue symptoms: Time course of single items between screening and week 8 (mean and $95 \%$ CI, FAS, $n=100$, LOCF).
Table 1. Sheehan Disability Scale (SDS): time course of total score and single items

\begin{tabular}{|c|c|c|c|c|c|c|}
\hline Item & Screening & Week 1 & Week 4 & Week 8 & $\begin{array}{l}\text { Difference } \\
\text { (week 8/screening) }\end{array}$ & p-Value ${ }^{*}$ \\
\hline $\begin{array}{c}\text { Total score (global } \\
\text { impairment) }\end{array}$ & $\begin{array}{l}17.0 \pm 5.0,17.5 \\
{[16.0 ; 18.0]^{\mathrm{a}}}\end{array}$ & $\begin{array}{l}13.2 \pm 5.2,14.0 \\
{[12.0 ; 15.0]}\end{array}$ & $\begin{array}{l}8.6 \pm 5.1,9.0 \\
{[7.0 ; 10.0]}\end{array}$ & $\begin{array}{l}4.7 \pm 4.3,4.0 \\
{[3.0 ; 5.0]}\end{array}$ & $\begin{array}{l}-12.3 \pm 6.3,-13.0 \\
{[-14.0 ;-11.0]}\end{array}$ & $<0.0001$ \\
\hline $\begin{array}{l}\text { Impairment work/ } \\
\text { school }\end{array}$ & $\begin{array}{l}5.7 \pm 2.0,6.0 \\
{[5.0 ; 6.0]}\end{array}$ & $\begin{array}{l}4.6 \pm 1.9,5.0 \\
{[5.0 ; 5.0]}\end{array}$ & $\begin{array}{l}3.0 \pm 1.9 \\
3.00[2.0 ; 3.0]\end{array}$ & $\begin{array}{l}1.7 \pm 1.5,1.0 \\
{[1.0 ; 2.0]}\end{array}$ & $\begin{array}{l}-4.0 \pm 2.3,-4.0 \\
{[-5.0 ;-3.0]}\end{array}$ & $<0.0001$ \\
\hline Impairment social life & $\begin{array}{l}5.4 \pm 2.1,6.0 \\
{[5.0 ; 6.0]}\end{array}$ & $\begin{array}{l}4.1 \pm 2.0,4.0 \\
{[4.0 ; 5.0]}\end{array}$ & $\begin{array}{l}2.8 \pm 1.8,3.0 \\
{[2.0 ; 3.0]}\end{array}$ & $\begin{array}{l}1.5 \pm 1.4,1.0 \\
{[1.0 ; 1.0]}\end{array}$ & $\begin{array}{l}-3.9 \pm 2.6,-4.0 \\
{[-5.0 ;-4.0]}\end{array}$ & $<0.0001$ \\
\hline $\begin{array}{l}\text { Family life/home re- } \\
\text { sponsibilities }\end{array}$ & $\begin{array}{l}5.9 \pm 2.0,6.0 \\
{[5.0 ; 7.0]}\end{array}$ & $\begin{array}{l}4.4 \pm 2.0,5.0 \\
{[4.0 ; 5.0]}\end{array}$ & $\begin{array}{l}2.8 \pm 1.8,3.0 \\
{[2.0 ; 3.0]}\end{array}$ & $\begin{array}{l}1.5 \pm 1.5,1.0 \\
{[1.0 ; 2.0]}\end{array}$ & $\begin{array}{l}-4.4 \pm 2.3,-5.0 \\
{[-5.0 ;-4.0]}\end{array}$ & $<0.0001$ \\
\hline Days lost & $\begin{array}{l}0.5 \pm 0.9,0.0 \\
{[0.0 ; 0.0]}\end{array}$ & $\begin{array}{l}0.2 \pm 0.6,0.0 \\
{[0.0 ; 0.0]}\end{array}$ & $\begin{array}{l}0.1 \pm 0.5,0.0 \\
{[0.0 ; 0.0]}\end{array}$ & $\begin{array}{l}0.1 \pm 0.5,0.0 \\
{[0.0 ; 0.0]}\end{array}$ & $\begin{array}{l}-0.4 \pm 0.8,0.0 \\
{[0.0 ; 0.0]}\end{array}$ & $<0.0001$ \\
\hline $\begin{array}{l}\text { Days underproduc- } \\
\text { tive }\end{array}$ & $\begin{array}{l}2.5 \pm 1.7,2.0 \\
{[2.0 ; 3.0]}\end{array}$ & $\begin{array}{l}1.6 \pm 1.6,1.0 \\
{[0.0 ; 1.0]}\end{array}$ & $\begin{array}{l}1.0 \pm 1.3,0.0 \\
{[0.0 ; 0.0]}\end{array}$ & $\begin{array}{l}0.7 \pm 1.2,0.0 \\
{[0.0 ; 0.0]}\end{array}$ & $\begin{array}{l}-1.8 \pm 1.8,-2.0 \\
{[-2.0 ;-1.0]}\end{array}$ & $<0.0001$ \\
\hline
\end{tabular}

Complement Med Res 2017;24:00-00 
Table 2. Recent Perceived Stress Questionnaire (PSQ-R): time course of total score and single items

\begin{tabular}{|c|c|c|c|c|c|}
\hline Item & Screening & Week 4 & Week 8 & $\begin{array}{l}\text { Difference } \\
\text { (week 8/screening) }\end{array}$ & p-Value \\
\hline PSQ-R stress score & $0.6 \pm 0.1,0.6[0.5 ; 0.6]^{\mathrm{a}}$ & $\begin{array}{l}0.4 \pm 0.1,0.4 \\
{[0.3 ; 0.4]}\end{array}$ & $\begin{array}{l}0.3 \pm 0.1,0.3 \\
{[0.3 ; 0.4]}\end{array}$ & $\begin{array}{l}-0.2 \pm 0.2,-0.2 \\
{[-0.3 ;-0.2]}\end{array}$ & $<0.0001$ \\
\hline \multicolumn{6}{|l|}{ Subscales } \\
\hline Harassment & $9.2 \pm 2.2,9.0[9.0 ; 10.0]$ & $\begin{array}{l}8.1 \pm 2.1,8.0 \\
{[8.0 ; 9.0]}\end{array}$ & $\begin{array}{l}7.3 \pm 2.1,7.0 \\
{[6.0 ; 8.0]}\end{array}$ & $\begin{array}{l}-1.9 \pm 2.2,-2.0 \\
{[-2.0 ;-1.0]}\end{array}$ & $<0.0001$ \\
\hline Overload & $11.9 \pm 2.3,12.0[12.0 ; 13.0]$ & $\begin{array}{l}10.9 \pm 2.3,11.0 \\
{[11.0 ; 12.0]}\end{array}$ & $\begin{array}{l}10.4 \pm 2.2,10.0 \\
{[10.0 ; 11.0]}\end{array}$ & $\begin{array}{l}-1.5 \pm 2.3,-1.0 \\
{[-2.0 ;-1.0]}\end{array}$ & $<0.0001$ \\
\hline Irritability & $5.7 \pm 1.2,6.0[5.0 ; 6.0]$ & $\begin{array}{l}4.3 \pm 1.4,4.0 \\
{[4.0 ; 5.0]}\end{array}$ & $\begin{array}{l}3.8 \pm 1.3,4.0 \\
{[4.0 ; 4.0]}\end{array}$ & $\begin{array}{l}-1.9 \pm 1.6,-2.0 \\
{[-2.0 ;-1.0]}\end{array}$ & $<0.0001$ \\
\hline Lack of joy & $18.2 \pm 3.2,18.0[17.0 ; 19.0]$ & $\begin{array}{l}14.9 \pm 3.4,15.0 \\
{[14.0 ; 16.0]}\end{array}$ & $\begin{array}{l}13.9 \pm 3.5,14.0 \\
{[13.0 ; 15.0]}\end{array}$ & $\begin{array}{l}-4.4 \pm 3.6,-4.0 \\
{[-5.0 ;-3.0]}\end{array}$ & $<0.0001$ \\
\hline Fatigue & $12.2 \pm 1.7,12.0[12.0 ; 13.0]$ & $\begin{array}{l}8.4 \pm 2.2,8.0 \\
{[8.0 ; 9.0]}\end{array}$ & $\begin{array}{l}7.4 \pm 2.2,7.0 \\
{[6.0 ; 8.0]}\end{array}$ & $\begin{array}{l}-4.8 \pm 2.5,-5.0 \\
{[-6.0 ;-4.0]}\end{array}$ & $<0.0001$ \\
\hline Worries & $12.5 \pm 2.7,12.0[11.0 ; 13.0]$ & $\begin{array}{l}9.9 \pm 2.3,10.0 \\
{[9.0 ; 10.0]}\end{array}$ & $\begin{array}{l}9.0 \pm 2.3,9.0 \\
{[8.0 ; 10.0]}\end{array}$ & $\begin{array}{l}-3.4 \pm 2.8,-3.0 \\
{[-4.0 ;-3.0]}\end{array}$ & $<0.0001$ \\
\hline Tension & $10.7 \pm 2.1,11.0[10.0 ; 12.0]$ & $\begin{array}{l}7.8 \pm 2.1,8.0 \\
{[7.0 ; 8.0]}\end{array}$ & $\begin{array}{l}7.0 \pm 2.0,7.0 \\
{[6.0 ; 7.0]}\end{array}$ & $\begin{array}{l}-3.8 \pm 2.8,-4.0 \\
{[-5.0 ;-3.0]}\end{array}$ & $<0.0001$ \\
\hline
\end{tabular}

${ }^{\mathrm{a}}$ Mean $\pm \mathrm{SD}$, median [95\% CI]

${ }^{*} \mathrm{p}$-Value of the 2-sided Wilcoxon signed-rank test, FAS, $\mathrm{n}=100$, LOCF. The $\mathrm{p}$-value refers to 'Difference (week $8 / \mathrm{screening}$ )'. $\mathrm{SD}=$ Standard deviation; $\mathrm{CI}=$ confidence interval; FAS = full analysis set; LOCF = last observation carried forward.

week 8. This also applies to the CGI therapeutic effect with a 'marked' or 'moderate' improvement in $84 \%$ of the trial participants at week 8 .

\section{Safety}

During the active treatment and the subsequent risk phase, $41 / 101$ (40.6\%) subjects experienced a total of 44 AEs, leading to an overall incidence rate of $0.007 \mathrm{AEs} /$ day of exposure. Most of the AEs (32/44 (72.7\%)) were assessed as 'not related' to the study drug. For 12/44 AEs (27.3\%) a causal relationship with the study drug could not be excluded but was assessed as 'unlikely' in all cases. In most of the cases, the intensity of the AE was mild (36/44 $(81.8 \%))$, otherwise moderate $(8 / 44(18.2 \%))$. None of the patients terminated the study prematurely because of AEs. The largest number of AEs referred to nervous system disorders and the gastrointestinal system, which corresponds to the study indication. One serious AE (SAE) occurred with a patient being hospitalized due to community-acquired pneumonia, which was assessed as not related to the study drug. None of the laboratory parameters presented a considerable mean change during the course of the study. No clinically relevant deviations in the 12-lead ECG and vital signs measurements at screening and week 8 were observed. A summary of the AE monitoring during the study is given in table 3.

\section{Compliance}

Compliance assessment was based on unused investigational product returned at the week 1 , week 4 and week 8 (termination) visits. A deviation concerning compliance was considered as relevant if the calculated compliance was $<80 \%$ or $>120 \%$. None of the subjects had to be excluded due to lack of investigational product compliance.
Table 3. AEs during active treatment and the 1-week risk phase

\begin{tabular}{ll}
\hline AE (MedDRA system organ class) & $\begin{array}{l}\text { Number of } \\
\text { patients }^{\mathrm{a}}\end{array}$ \\
\hline Any patients with AE(s) & 41 \\
Cardiac disorders & 2 \\
Gastrointestinal disorders & 8 \\
General disorders and administration site conditions & 4 \\
Hepatobiliary disorders & 1 \\
Infections and infestations & 7 \\
Investigations & 1 \\
Metabolism and nutrition disorders & 1 \\
Musculoskeletal and connective tissue disorders & 3 \\
Nervous disorders & 9 \\
Psychiatric disorders & 3 \\
Renal and urinary disorders & 1 \\
Reproductive system and breast disorders & 2 \\
Respiratory, thoracic and mediastinal disorders & 2 \\
\hline
\end{tabular}

${ }^{a}$ Absolute frequency, safety analysis set (SAF), $\mathrm{n}=101$.

$\mathrm{AE}=$ Adverse event; MedDRA $=$ Medical Dictionary for Regulatory Activities .

\section{Discussion}

The values of nearly all outcome variables improved markedly over time, with none of them increasing. While a substantial alleviation of symptoms could already be observed after the first week of treatment, the symptoms continued to decline until the final evaluation at week 8 .

The MFI-20 analysis shows significant improvement in all subscales over the duration of the treatment, with the most marked changes in the subscale 'general fatigue'. A less pronounced impact 
was observed for the subscale 'reduced motivation', which, however, may be explained by the relatively low baseline values.

The evaluation of results assessed by the NASs for chronic fatigue symptoms according to CDC revealed a significant improvement between the screening visit and the following visits. The degrees of improvement were similar among the different scales and suggest an overall beneficial effect of $R$. rosea on the capability to recover from mental or physical stress (items 'postexertional malaise' and 'unrefreshing sleep'), as well as on mental performance (item 'impairment of memory and concentration') (fig. 2). These findings indicate a therapeutic effect of WS ${ }^{\circledR} 1375$ on chronic fatigue-related symptoms. A broad application range in conditions of fatigue and a possible inhibition of the development of chronic fatigue from minor fatigue presentations through $R$. rosea administration are thus suggested. The findings are in line with publications reporting the beneficial effect of $R$. rosea on physical and mental performance [22-24] and are further supported by the favorable results achieved for the NCT in this trial.

The impairments regarding everyday activities and normal functioning that are imposed upon patients by fatigue conditions were measured by means of the SDS. Significant improvement was demonstrated for most values assessed in week 8 compared to baseline. Like the 'global impairment' score, also the outcome measures for the subscores 'impairment at work', 'impairment in social life', and 'impairment in family life' improved considerably (table 2), thus suggesting a beneficial impact on quality of life through improved fatigue symptoms.

The screening score index of the PSQ-R indicates significant preexisting perceived stress in our study population, since this value corresponds to the upper quartile according to the validation study by Levenstein et al. [34]. The results obtained in this trial show that until week 8 the score index decreased, finally reaching the second quartile. This is a statistically significant and clinically relevant alleviation of stress symptoms, in which 'fatigue' was found to be the subscore with the highest improvement values among the PSQ-R values assessed (table 2).

The analysis of the BDI-II revealed a rather low mean total score at screening (10.8 \pm 5.0$)$, which indicates only minimal depression in our study population. Still, the mean total score of the BDI-II significantly decreased at weeks 4 and 8 , which suggests a beneficial effect of WS ${ }^{\circledR} 1375$ on the symptoms of depression in patients suffering from prolonged or chronic fatigue. This finding supports the results obtained by Olsson et al. [26], who reported a marked beneficial effect of $R$. rosea on both fatigue- and depression-related symptoms as measured by the Pines burnout scale and the Montgomery-Asberg depression rating scale (MADRS), respectively.

The results of the CGI scales also indicate considerable efficacy ratings for $\mathrm{WS}^{\circledR} 1375$ in the treatment of fatigue and thus correspond to the results of the patient-rated assessments described above. According to the CGI rating, the vast majority of the trial participants experienced a marked improvement of their fatigue symptoms after 8 weeks of treatment with $2 \times 200$ mg WS $^{\circledR} 1375$ as compared to baseline. Similar results were obtained regarding the therapeutic effect of the $R$. rosea extract.
The consistent results obtained in this trial were also confirmed by analyses of repeated measurements. Our findings indicate that the favorable impact of $\mathrm{WS}^{\circledR} 1375$ in patients suffering from prolonged or chronic fatigue was not restricted to core fatigue symptoms such as physical fatigue, mental fatigue, reduced activity, or prolonged exhaustion, as evaluated by the MFI-20 and the respective NASs. The marked improvement also encompassed many of the attending symptoms like depression (BDI-II), reduced sleep quality (PSQI), subjectively experienced stress (PSQ-R), and impaired executive function (NCT). These single aspects also translated into an improved overall outcome and positive impact on many aspects of everyday life, as indicated by the improvement in the CGI and SDS scales. Our results thus confirm published findings from research on the adaptogenic properties [15-17] and related therapeutic effects of $R$. rosea [22-26] and prove the applicability of these findings to the target group studied in this trial. The patients in this study showed only overlapping low levels of depressive symptoms with a low initial BDI-II score. Nevertheless, the BDI-II score decreased even further during the course of the study treatment.

$\mathrm{WS}^{\circledR} 1375$ presented a favorable safety profile. Most of the AEs were of mild intensity and not or not likely to be related to treatment. Given the favorable results of the efficacy and safety assessments obtained over the 8-week course of the study presented here, this trial marks an important step towards the future long-term testing of efficacy and tolerability of $R$ rosea in fatigue patients.

\section{Shortcomings}

Due to the exploratory character of the trial, no adjustments for multiplicity were made. Nevertheless, while exploratory analyses cannot claim to be confirmatory, they do allow the revelation of trends if applicable and the generation of hypotheses for future research. Also, these types of studies explore the usefulness for the targeted indication and provide bases for confirmatory study design, endpoints and methodologies [38].

Another limitation of this trial is the lack of a control. Notable in this context is a work by Cho et al. [39] who conducted a systematic review and meta-analysis of the placebo response in CFS. The result showed a pooled placebo response of $19.6 \%$ (95\% CI 15.4-23.7\%), which was thus significantly lower than expected. However, as the patients of the present study were suffering from prolonged or chronic fatigue but not from CFS, this finding may be only partly applicable. Even though the literature provides quite a few reports on clinical trials suggesting the possible success of treating fatigue symptoms with antidepressants [40], medical therapies have to date only played a minor role in the treatment of CFS and fatigue symptoms in general, which instead tend to be treated with exercise therapy or cognitive behavioral therapy [41].

The consistent results regarding the effects of WS ${ }^{\circledR} 1375$ on all outcome parameters and the ongoing improvement over time are noteworthy. This encourages expectations that a long-term, placebo-controlled trial in patients with fatigue symptoms could show positive results for $\mathrm{WS}^{\circledR} 1375$ with respect to prolonged or chronic fatigue and related symptoms. 


\section{Conclusions}

In this open-label, single-arm trial the administration of $2 \times$ 200 mg WS ${ }^{\circledR} 1375$ over 8 weeks significantly improved prolonged or chronic fatigue symptoms. The safety and tolerability of WS ${ }^{\circledR}$ 1375 also presented a favorable profile.

\section{Ethical Statement}

We herewith confirm that the trial protocol has been approved by the Central Ethics Commission of the Ministry of Healthcare of Ukraine and meets the standards of the Declaration of Helsinki in its revised version of 1975 and its amendments of 1983, 1989, and 1996 (JAMA 1997;277:925-926).

\section{Disclosure Statement}

A.W. is employee of Dr. Willmar Schwabe GmbH \& Co. KG, the sponsor of the trial. Y.L. officiated as an investigator in this trial and received remuneration accordingly. I.Z. received honoraria from Dr. Willmar Schwabe GmbH \& Co. KG.

\section{Acknowledgements}

The study was sponsored by Dr. Willmar Schwabe GmbH \& Co. KG, Germany. EudraCT No. 2010-019818-24, Study No. 578001.01.011.

\section{References}

1 Jordá FC, López Vivancos J: Fatigue as a determinant of health in patients with celiac disease. J Clin Gastroenterol 2010;44:423-427.

2 Yunus MB, Aldag JC: The concept of incomplete fibromyalgia syndrome: comparison of incomplete fibromyalgia syndrome with fibromyalgia syndrome by 1990 ACR classification criteria and its implications in clinical practice. J Clin Rheumatol 2012;18:71-75.

3 CDC Centers for Disease Control and Prevention. www.cdc.gov/cfs/diagnosis/index.html (last updated May 14, 2012).

4 Avellaneda Fernández A, Pérez Martín A, Izquierdo Martínez M, Arruti Bustillo M, Barbado Hernández FJ, de la Cruz Labrado J, Díaz-Delgado Peñas R, Gutiérrez Rivas E, Palacín Delgado C, Rivera Redondo J, Ramón Giménez JR: Chronic fatigue syndrome: aetiology, diagnosis and treatment. BMC Psychiatry 2009;9(suppl 1):S1.

5 van't Leven M, Zielhuis GA, van der Meer JW, Verbeek $\mathrm{AL}$, Bleijenberg G: Fatigue and chronic fatigue syndrome-like complaints in the general population. Eur J Public Health 2010;20:251-257.

6 Aritake S, Kaneita Y, Ohtsu T, Uchiyama M, Mishima K, Akashiba T, Uchimura N, Nakaji S, Munezawa T, Ohida T: Prevalence of fatigue symptoms and correlations in the general adult population. Sleep Biol Rhythms 2015;13:146-154

7 Loge JH, Ekeberg $\varnothing$, Kaasa S: Fatigue in the general Norwegian population: normative data and associations. J Psychosom Res 1998;45:53-65.

8 Watanabe N, Stewart R, Jenkins R, Bhugra DK, Furukawa TA: The epidemiology of chronic fatigue, physical illness, and symptoms of common mental disorders: a cross-sectional survey from the second British $\mathrm{Na}$ tional Survey of Psychiatric Morbidity. J Psychosom Res 2008;64:357-362.

9 Yancey JR, Thomas SM: Chronic fatigue syndrome: diagnosis and treatment. Am Fam Physician 2012;86: 741-746.

10 Gambert SR: Why do I always feel tired? Evaluating older patients reporting fatigue. Consultant 2013;53:785-789.

11 Brekhman II, Dardymov IV: New substances of plant origin which increase nonspecific resistance. Annu Rev Pharmacol 1969;9:419-430.

12 Lutgendorf SK, Antoni MH, Fletcher MA, Penedo F, Baum A, Schneiderman N, Klimas N: Physical symptoms of chronic fatigue syndrome are exacerbated by the stress of Hurricane Andrew. Psychosom Med 1995;57:310-323.

13 Milczarek M, Schneider E, Gonzalez ER: OSH in Figures: Stress at Work - Facts and Figures. Luxembourg, European Agency for Safety and Health at Work, Office for Official Publications of the European Communities, 2009, pp 20-28.
14 Plieger T, Melchers M, Montag C, Meermann R, Reuter M: Life stress as potential risk factor for depression and burnout. Burnout Res 2015;2:19-24.

15 Khanum F, Bawa AS, Singh B: Rhodiola rosea: a versatile adaptogen. Compr Rev Food Sci Food Saf 2005;4:55-62.

16 Kelly GS: Rhodiola rosea: a possible plant adaptogen. Altern Med Rev 2001;6:293-302.

17 Panossian A, Wikman G, Sarris J: Rosenroot (Rhodiola rosea): traditional use, chemical composition, pharmacology and clinical efficacy. Phytomedicine 2010;17: 481-493.

18 Brown RP, Gerbarg PL, Ramazanov Z: Rhodiola rosea. A phytomedicinal overview. HerbalGram 2002;56:40-52.

19 Ramazanov Z: Phytochemistry, pharmacology and standardization of Rhodiola rosea root extract. National BioScience Corporation, http://rhodiolarosea.org/ Phtyo_Pharm_Stand_Of_RR_original.pdf, 2002.

20 Panossian A, Wikman G: Evidence-based efficacy of adaptogenes in fatigue, and molecular mechanisms re lated to their stress-protective activity. Curr Clin Pharmacol 2009;4:98-219.

21 EMEA/HMPC/232091/2011. Community herbal mon ograph on Rhodiola rosea L., rhizoma et radix. Final 27 March 2012. London, Committee on Herbal Medicinal Products (HMPC), EMA.

22 Darbinyan V, Kteyan A, Panossian A, Gabrielian E, Wikman G, Wagner H: Rhodiola rosea in stress induced fatigue - a double blind cross-over study of a standardized extract SHR-5 with a repeated low-dose regimen on the mental performance of healthy physicians during night duty. Phytomedicine 2000;7:365-371.

23 Shevtsov VA, Zholus BI, Shervarly VI, Vol'skij VB, Korovin YP, Khristich MP, Roslyakova NA, Wikman G: A randomized trial of two different doses of a SHR-5 rosalin versus placebo and control of capacity for mental work. Phytomedicine 2003;10:95-105.

24 Spasov AA, Wikman GK, Mandrikov VB, Mironova IA, Neumoin VV: A double-blind, placebo-controlled pilot study of the stimulating and adaptogenic effect of Rhodiola rosea SHR-5 extract on the fatigue of students caused by stress during an examination period with a repeated low-dose regimen. Phytomedicine 2000;7:85-89.

25 Edwards D, Heufelder A, Zimmermann A: Therapeutic effects and safety of Rhodiola rosea extract WS ${ }^{\circledR} 1375$ in subjects with life-stress symptoms - results of an open-label study. Phytother Res 2012;26:1220-1225.

26 Olsson EM, von Schéele B, Panossian A: A randomised, double-blind, placebo-controlled, parallel-group study of the standardised extract SHR- 5 of the roots of Rhodiola rosea in the treatment of subjects with stress-related fatigue. Planta Med 2009;75:105-112.
27 Saratikov AS: The Golden Root (Rhodiola rosea), ed 2. Tomsk, Publishing House of Tomsk University, 1974.

28 Ishaque S, Shamseer L, Bukutu C, Vohra S: Rhodiola rosea for physical and mental fatigue: a systematic review. BMC Complement Altern Med 2012;12:70.

29 Smets EM, Garssen B, Bonke B, De Haes JC: The Multidimensional Fatigue Inventory (MFI) psychometric qualities of an instrument to assess fatigue. J Psychosom Res 1995;39:315-325.

30 Lin JM, Brimmer DJ, Maloney EM, Nyarko E, Belue R Reeves WC: Further validation of the Multidimensional Fatigue Inventory in a US adult population sample. Popul Health Metr 2009;7:18.

31 Oswald WD, Roth E: Der Zahlen-Verbindungs-Test (ZVT). Ein sprachfreier Intelligenz-Test zur Messung der «kognitiven Leistungsgeschwindigkeit». Handanweisung, ed 2. Göttingen, Hogrefe, 1987

32 Sheehan DV, Harnett-Sheehan K, Raj BA: The measurement of disability. Int Clin Psychopharmacol 1996; 11(suppl 3):89-95.

-33 Buysse DJ, Reynolds CF 3rd, Monk TH, Berman SR, Kupfer DJ: The Pittsburgh Sleep Quality Index: a new instrument for psychiatric practice and research. Psychiatry Res 1989;28:193-213.

34 Levenstein S, Prantera C, Varvo V, Scribano ML, Berto E, Luzi C, Adreoli A: Development of the perceived stress questionnaire: a new tool for psychosomatic research. J Psychosom Res 1993;37:19-32.

35 Beck AT, Steer RA, Brown GK: Manual for the Beck Depression Inventory-II. San Antonio, Psychological Corporation, 1996

36 Guy W: Clinical Global Impression. ECDEU Assessment Manual for Psychopharmacology, revised. Rockville, National Institute of Mental Health, 1976, pp 217-222.

37 Guo X, Johnson WD: Sample sizes for experiments with multivariate repeated measures. J Biopharm Stat 1996;6:155-176.

38 EMA/CPMP/ICH/291/95. ICH Topic E 8: General Considerations for Clinical Trials. EMA, London, 1998. www.ema.europa.eu.

39 Cho HJ, Hotopf M, Wessely S: The placebo response in the treatment of chronic fatigue syndrome: a systematic review and meta-analysis. Psychosom Med 2005;67: 301-313.

40 O’Malley PG, Balden E, Tomkins G, Santoro J, Kroenke K, Jackson JL: Treatment of fibromyalgia with antidepressants: a meta-analysis. J Gen Intern Med 2000; 15:659-666.

41 Amihăesei IC, Cojocaru E: Main neuroendocrine features, diagnosis and therapeutic possibilities in the chronic fatigue syndrome, an underdiagnosed entity. Rev Med Chir Soc Med Nat Iasi 2014·118:688-691. 